\title{
Influence of Load Changes on Tricuspid Inflow
}

\author{
E. MANDYSOVÁ, P. NIEDERLE \\ Hospital Na Homolce, Prague, Czech Republic
}

Received March 7, 2006

Accepted June 13, 2006

On-line available June 22, 2006

\begin{abstract}
Summary
In healthy subjects, the right ventricular filling pattern estimated from tricuspid valve inflow is highly load-dependent. This can be clearly demonstrated by changes of Doppler inflow tracings recorded during tidal breathing at rest. The aim of our study was to test the magnitude of tricuspid inflow changes during more pronounced load changes induced by

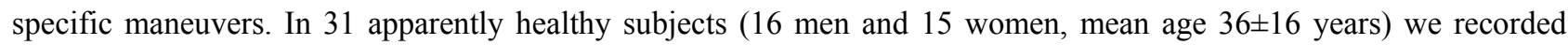
pulsed Doppler tracings of tricuspid inflow during forced inspiration, elevation of lower extremities (increased preload) and handgrip exercise (increased afterload). The obtained values were compared with end-expiratory phase of tidal breathing at rest. We found a significantly larger increase in the early and late filling velocities (for $\mathrm{E}$ and $\mathrm{A} \mathrm{p}<0.001$ ) under the conditions of increasing preload (elevation of legs) and less pronounced, but still significant changes with isometric exercise (for $\mathrm{E} \mathrm{p}<0.001$ and for $\mathrm{A} \mathrm{p}<0.01$ ). We conclude that the right ventricular filling pattern in healthy humans is highly load-sensitive and for this reason the effect of any intervention (e.g. pharmacological) must be studied under strict and well-defined resting conditions.
\end{abstract}

\section{Key words}

Pulsed Doppler • Tricuspid valve flow $\bullet$ Physiological variations $\bullet$ Load dependence

\section{Introduction}

Pulsed Doppler echocardiography represents a non-invasive method for the evaluation of the left ventricular diastolic characteristics in healthy (Spirito et al. 1988) as well as in diseased subjects (Rokey et al. 1985) and the same is true for the right ventricle. However, in the past, relatively low interest was paid to the right ventricular diastolic function. This situation changed with the development of new echocardiographic techniques, especially tissue Doppler (McDicken et al. 1992). Moreover, the classical echocardiographic approaches have been addressed (Meluzín et al. 2005) as have M-mode of the tricuspid annulus motion (Emilsson et al. 2005) and the pulsed Doppler flow velocities of the tricuspid flow.

Load dependence may play an important role in the character of the transvalvular flow pattern. This is particularly true for the tricuspid inflow where the changes of pre- and afterload are more pronounced than in the mitral one (Dabestani et al. 1988).

Modern research studies emphasize pronounced respiratory variations of the tricuspid flow and the need to compare the measurements from the same phases of the respiratory cycle (Pye et al. 1991). However, to date, only few data are available concerning the physiologic respiratory tricuspid flow variations and the influence of preload and afterload changes on the tricuspid flow 
pattern (Mandysová et al. 1995).

The aim of our study was to test the response of tricuspid inflow to changes of load conditions in healthy volunteers.

\section{Methods}

The study was performed on 35 healthy volunteers ( 20 men and 15 women), mean age $36 \pm 16$ years, with a negative cardiologic or pneumologic history and normal physical examination. They all signed a written informed consent form for the echo study. Four men from the original group were excluded because their tricuspid flow tracings were of unsatisfactory quality, so that pulsed Doppler signals were evaluated from 31 subjects only.

\section{Echocardiography}

Pulsed wave Doppler (PWD) signals of tricuspid flow were recorded with a $2.5 \mathrm{MHz}$ probe (Sonos 1000, Hewlett Packard). The signal was evaluated from a slightly modified approach between the apical four chamber and parasternal longitudinal axis view. From this approach it was possible to gain the best quality tricuspid flow signals with the lowest interference from the moving walls. This view was chosen to achieve the smallest angle $\left(<20^{\circ}\right)$ between the direction of blood flow and the ultrasound beam. The sample volume of $0.12 \mathrm{~cm}^{2}$ was placed between the tips of the tricuspid leaflets. Simultaneously with the PWD tracings, ECG and respiratory curves were registered. Appropriate filter settings together with a low velocity signal range were used to optimize the image quality. The tricuspid valve exhibited normal morphology in all the subjects studied.

Doppler tracings were registered during inhalation and exhalation at rest and during a forced inspiration. Another trace was taken at the instant of an acute increase of preload (caused by elevation of lower limbs on a tilt table inclined at 60 degrees above the horizontal line) and afterload (the handgrip test). The handgrip trace was recorded while the subject gripped the dynamometer balloon as tightly as possible with the right hand for $2 \mathrm{~min}$. Each tested person was instructed to breathe quietly during the test to avoid Valsalva maneuver. Doppler tracings were obtained immediately after lower limb elevation and at the peak of the isometric exercise.

The PWD signal was registered on a video tape with the speed of $100 \mathrm{~mm} / \mathrm{s}$ and evaluation of the spectral

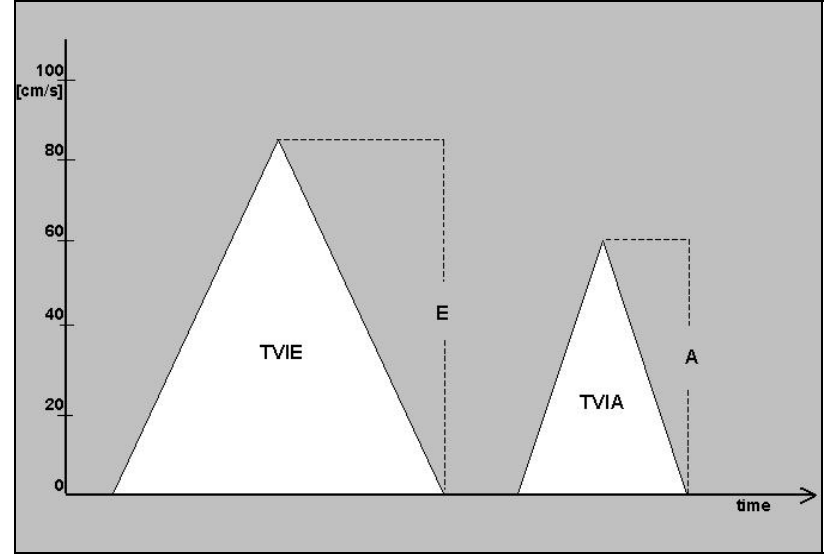

Fig. 1. Scheme of measurements. $A=$ peak velocity of $A$ wave, $E$ $=$ peak velocity of $E$ wave, TVIA = flow velocity integral of $A$ wave, TVIE $=$ flow velocity integral of $\mathrm{E}$ wave

Table 1. Pulsed Doppler parameters of the right ventricular diastolic filling: variation coefficients of intra-individual and interindividual variability $(n=10)$.

\begin{tabular}{llll}
\hline $\begin{array}{l}\text { Variation } \\
\text { coefficient }\end{array}$ & $\begin{array}{l}\mathbf{E} \\
{[\mathbf{c m} / \mathbf{s}]}\end{array}$ & $\begin{array}{l}\mathbf{A} \\
{[\mathbf{c m} / \mathbf{s}]}\end{array}$ & $\mathbf{E} / \mathbf{A}$ \\
\hline $\begin{array}{l}\text { Intra-individual } \\
\text { Inter-individual }\end{array}$ & 1.9 & 3.1 & 3.2 \\
\hline
\end{tabular}

curves was performed off line. The following parameters of the diastolic tricuspid flow were measured (Fig. 1): peak velocity of early diastolic filling rate $\mathrm{E}\left(\mathrm{cm} . \mathrm{s}^{-1}\right)$ and time velocity integral of early diastolic filling TVIE $(\mathrm{cm})$, peak velocity of late diastolic filling rate $\mathrm{A}\left(\mathrm{cm} . \mathrm{s}^{-1}\right)$ and time velocity integral of late diastolic filling TVIA $(\mathrm{cm})$ and their ratios (E/A and TVIE/TVIA). Each value represented an average of measurements from five heart cycles.

Tricuspid flow variables from the expiratory phase (exp) of tidal breathing served as reference for comparison with the variables registered during the inspiratory phase (insp) of tidal breathing, in forced inspiration, in breathing out phase after lower limb elevation $\left({ }_{\mathrm{el}}\right)$ and in the breathing out phase during the handgrip (hg). Concerning tidal breathing, the spectral curve with the lowest early peak velocity was chosen from the expiratory phase and the highest early peak velocity from the inspiratory one.

\section{Reproducibility}

To assess the variability of repeated measurements, the following parameters were tested: 
Table 2. Pulsed Doppler parameters of tricuspid flow - preload and afterload changes.

\begin{tabular}{lllll}
\hline & Breath out phase & Breath in phase & $\begin{array}{l}\text { Elevation of the lower } \\
\text { extremities }\end{array}$ & Isometric exercise \\
\hline$E\left[\mathrm{~cm}^{-1} \mathrm{~s}^{-1}\right]$ & $49.8 \pm 8.0$ & $64.2 \pm 9.4$ & $70.6 \pm 14.2$ & $52.9 \pm 8.6$ \\
& & $\mathrm{p}=0.001$ & $\mathrm{p}=0.001$ & $\mathrm{p}=0.005$ \\
A $\left[\mathrm{cm} \cdot \mathrm{s}^{-1}\right]$ & $34.0 \pm 6.6$ & $40.3 \pm 7.7$ & $42.0 \pm 10.5$ & $36.9 \pm 7.1$ \\
& & $\mathrm{p}=0.001$ & $\mathrm{p}=0.001$ & $\mathrm{p}=0.01$ \\
E/A & $1.5 \pm 0.3$ & $1.6 \pm 0.3$ & $1.7 \pm 0.3$ & $1.5 \pm 0.3$ \\
& & $\mathrm{p}=0.005$ & $\mathrm{p}=0.001$ & $\mathrm{NS}$ \\
TVIE [cm] & $10.2 \pm 2.9$ & $11.5 \pm 2.2$ & $12.6 \pm 2.9$ & $9.3 \pm 1.8$ \\
& & $\mathrm{p}=0.001$ & $\mathrm{p}=0.001$ & $\mathrm{NS}$ \\
TVIA [cm] & $4.7 \pm 1.6$ & $6.0 \pm 1.7$ & $6.6 \pm 1.7$ & $5.7 \pm 1.9$ \\
& & $\mathrm{p}=0.001$ & $\mathrm{p}=0.001$ & $\mathrm{p}=0.003$ \\
TVIE $/$ TVIA & $2.4 \pm 1.2$ & $2.1 \pm 0.7$ & $2.1 \pm 1.0$ & $1.8 \pm 0.6$ \\
& & $\mathrm{NS}$ & $\mathrm{NS}$ & $\mathrm{p}=0.001$ \\
\hline
\end{tabular}

Data are mean \pm S.D.

early diastolic filling rate $\mathrm{E}$, late diastolic filling rate $\mathrm{A}$ and their rate $\mathrm{E} / \mathrm{A}$. The variation coefficients of the measured parameters are shown in Table 1. Intraindividual variability was calculated from a paired evaluation recorded on the same day by the same observer under standard conditions, inter-individual variability was calculated by comparing the results obtained by both observers, registering the signals from the same person examined on the same day.

\section{Statistics}

Measured values are presented as mean \pm S.D. Student's paired t-test was used for the identification of differences between each of the studied groups. $\mathrm{p}<0.05$ values were considered to be statistically significant.

Data inspection showed that values between phases were at least slightly shifted in one direction for all three investigated variables in all subjects. We performed Two Samples Sign Test formally, but the significance was self-evident. As distribution of observed variables was normally shaped, we then applied Student's paired t-test that also confirmed difference. Normality of groups was not formally tested. The results for means were used in the article, as we considered them more illustrative.

\section{Results}

There was a significant variation of the peak $E$ wave velocity depending on the respiratory phase during tidal breathing (Table 2): $\mathrm{E}_{\exp }=49.8 \pm 6.6 \mathrm{~cm} / \mathrm{s}, \mathrm{E}_{\text {insp }}=$ $64.2 \pm 9.4 \mathrm{~cm} / \mathrm{s}(\mathrm{p}=0.001)$. Respiratory variations of the peak $\mathrm{A}$ wave velocity were less pronounced $\left(\mathrm{A}_{\exp }=\right.$ $34.0 \pm 6.6 \mathrm{~cm} / \mathrm{s}, \mathrm{A}_{\text {insp }}=40.3 \pm 7.7 \mathrm{~cm} / \mathrm{s}$ ) but also highly statistically significant $(p=0.001)$. Similarly, $E / A_{\exp }=$ $1.5 \pm 0.3$ and $E / A_{\text {insp }}=1.6 \pm 0.3(p=0.005)$. The values of the time velocity integrals of early diastolic filling phase also significantly oscillated with tidal breathing (TVIE exp $=10.2 \pm 2.9 \mathrm{~cm}$, TVIE $_{\text {insp }}=11.5 \pm 2.2 \mathrm{~cm}, \mathrm{p}=0.001$ ) as well as the time velocity integrals of the late diastolic filling phase TVIA $_{\text {exp }}=4.7 \pm 1.6 \mathrm{~cm}$, TVIA $_{\text {insp }}=6.0 \pm 1.7 \mathrm{~cm}$, $\mathrm{p}=0.001$ ). On the other hand, the rate of the integrals of early and late diastolic filling did not change significantly $\left(\right.$ TVIE$_{\text {TVIA }}$ exp $\left.=2.4 \pm 1.2, \mathrm{TVIE}_{\mathrm{TVIA}} \mathrm{Tnsp}_{\mathrm{i}}=2.1 \pm 0.7 \mathrm{NS}\right)$.

The PWD signal registered at the top of forced inspiration was of a very poor quality did not allow proper measurements in 28 of 31 subjects. The main cause for this we consider to be the inspiratory interposition of the inflated lungs between the heart and the ultrasonic probe.

Differences in the measured parameters were even more pronounced between supine position and passive elevation of the lower extremities (both measured in the normal breathing out phase): $\mathrm{E}_{\exp }=49.8 \pm 6.6 \mathrm{~cm} / \mathrm{s}$, $\mathrm{E}_{\mathrm{el}}=70.1 \pm 4.2 \mathrm{~cm} / \mathrm{s}, \mathrm{p}=0.001 ; \mathrm{A}_{\exp }=34.0 \pm 6.6 \mathrm{~cm} / \mathrm{s}, \mathrm{A}_{\mathrm{el}}=$ $42.0 \pm 10.5 \mathrm{~cm} / \mathrm{s}, \mathrm{p}=0.001$, similarly the rates of peak velocities: $\mathrm{E} / \mathrm{A}_{\exp }=1.5 \pm 0.3, \mathrm{E} / \mathrm{A}_{\mathrm{el}}=1.7 \pm 0.3, \mathrm{p}=0.001$. The values of the time velocity integrals also increased substantially with this maneuver, reaching a greater variance of their values: TVIE $_{\exp }=10.2 \pm 2.9 \mathrm{~cm}$, TVIE $_{\mathrm{el}}=$ 
Table 3. Correlation of particular expiratory PWD parameters with those recorded under different preload (insp, el) and afterload $(h g)$ conditions.

\begin{tabular}{|c|c|c|}
\hline Correlated variables & $\mathbf{r}$ & $\mathbf{p}$ \\
\hline \multicolumn{3}{|l|}{ peak velocities } \\
\hline$E_{\text {exp }} v s E_{\text {insp }}$ & 0.794 & $<0.001$ \\
\hline$E_{\text {exp }} v s E_{e l}$ & 0.543 & $<0.001$ \\
\hline$E_{\text {exp }} v s E_{h g}$ & 0.760 & $=0.005$ \\
\hline$A_{\text {exp }} v s A_{\text {insp }}$ & 0.661 & $<0,001$ \\
\hline$A_{e x p} v s A_{e l}$ & 0.622 & $<0.001$ \\
\hline$A_{\text {exp }} v s A_{h g}$ & 0.623 & $=0.013$ \\
\hline$E / A_{\text {exp }} v s E / A_{\text {insp }}$ & 0.609 & $=0.005$ \\
\hline$E / A_{\exp } v s E / A_{e l}$ & 0.361 & $=0.001$ \\
\hline$E / A_{\exp } v s E / A_{h g}$ & 0.483 & $=0.730$ \\
\hline$T V I E_{\text {exp }}$ vs TVIE $E_{\text {insp }}$ & 0.858 & $<0,001$ \\
\hline$T V I E_{e x p} v s T V I E_{e l}$ & 0.644 & $<0.001$ \\
\hline$T V I E_{\text {exp }}$ vs $T V I E_{h g}$ & 0.495 & $=0.066$ \\
\hline
\end{tabular}

\section{time velocity integrals}

\begin{tabular}{|c|c|c|}
\hline$T V I A_{\text {exp }}$ vs TVIA insp & 0.308 & $=0.001$ \\
\hline$T V I A_{\text {exp }}$ vs $T V I A_{e l}$ & 0.382 & $<0.001$ \\
\hline$T V I A_{\text {exp }}$ vs $T V I A_{h g}$ & 0.504 & $=0.003$ \\
\hline$T V I E / T V I A_{\text {exp }}$ vs TVIE/TVIA ${ }_{\text {insp }}$ & 0.522 & $=0.068$ \\
\hline$T V I E / T V I A_{e x p} v s$ TVIE/TVIA $A_{e l}$ & 0.539 & $=0.071$ \\
\hline TVIE/TVIA $A_{\text {exp }}$ vs TVIE/TVIA $A_{h g}$ & 0.542 & $=0.001$ \\
\hline
\end{tabular}

$12.6 \pm 2.9 \mathrm{~cm}, \mathrm{p}=0.001, \mathrm{TVIA}_{\text {exp }}=4.7 \pm .6 \mathrm{~cm}, \mathrm{TVIA}_{\mathrm{el}}=$ $6.6 \pm 1.7 \mathrm{~cm}, p=0.001$. The rate of both the integrals did not change significantly: TVIE/TVIA exp $=2.4 \pm 1.2$, $\mathrm{TVIE} / \mathrm{TVIA}_{\mathrm{el}}=2.1 \pm 1.0, \mathrm{NS}$.

Peak velocities of the early and the late diastolic filling rate increased only slightly with isometric exercise: Nevertheless, they reached statistical significance due to the one way shift of the values in a paired observation: $\mathrm{E}_{\exp }=49.8 \pm 6.6 \mathrm{~cm} / \mathrm{s}, \mathrm{E}_{\mathrm{hg}}=53.0 \pm 8.6$ $\mathrm{cm} / \mathrm{s}, \mathrm{p}=0.005 ; \mathrm{A}_{\text {exp }}=34.0 \pm 6.6 \mathrm{~cm} / \mathrm{s}, \mathrm{A}_{\mathrm{hg}}=37.0 \pm 7.1$ $\mathrm{cm} / \mathrm{s}, \mathrm{p}=0.01$. On the other hand, no significant increase of $\mathrm{E} / \mathrm{A}$ rate was observed: $\mathrm{E} / \mathrm{A}_{\exp }=1.5 \pm 0.3, \mathrm{E} / \mathrm{A}_{\mathrm{hg}}=$ $1.5 \pm 0.3$, NS. The same was true with the time velocity integral of the early diastolic filling $\left(\mathrm{TVIE}_{\exp }=10.2 \pm 2.9\right.$ $\left.\mathrm{cm}, \mathrm{TVIE}_{\mathrm{hg}}=9.3 \pm 1.8 \mathrm{~cm}, \mathrm{NS}\right)$. As the filling integral increased significantly $\left(\mathrm{TVIA}_{\text {exp }}=4.7 \pm 1.6 \mathrm{~cm}, \mathrm{TVIA}_{\mathrm{hg}}=\right.$ $5.7 \pm 1.9 \mathrm{~cm}, \mathrm{p}=0.003)$, the rate of both the intervals statistically significantly decreased $\left(\mathrm{TVIE} / \mathrm{TVIA}_{\exp }=\right.$ $2.4 \pm 1.2, \mathrm{TVIE} \mathrm{TVIA}_{\mathrm{hg}}=1.8 \pm 0.6, \mathrm{p}=0.001$ ).

All types of load changes caused the shift of $\mathrm{E}$ and $A$ values systematically in one direction (with no exception). So even slight changes of values (as can be seen with handgrip) appear as statistically significant. On the other hand, there were relatively high interpersonal differences in these shifts that can be demonstrated by relatively great S.D. values and thus low correlation coefficients (Table 3).

\section{Discussion}

Tricuspid flow represents a complex event, influenced by many concurrently acting variables. The shape of the diastolic tricuspid flow velocity curves is influenced not only by the right ventricular relaxation, compliance and viscoelastic properties but also by the right atrial pressure at the time of tricuspid valve opening as well as the right ventricular load at the end of diastole. The properties of the pericardium together with interventricular interaction cannot also be neglected (Appleton et al. 1992).

The increasing number of heart failure patients highlights the need for a simple non-invasive evaluation of the RV function in clinical practice (Lindqvist et al. 2005). However, for a correct interpretation of the Doppler tricuspid flow profile in pathological conditions it is necessary to fix its physiological variations.

Peak values of the diastolic flow velocities from the tricuspid valve flow are lower than those from the mitral one and their signal quality is rather low. The difficulties with the accurate measurement can represent one of the reasons why they were not often studied (Hatle et al. 1989, Chakko et al. 1990) and that relatively large differences in values have been reported (Table 4).

Recently, the influence of aging on right ventricular filling velocities has been studied with different results. Lindqvist et al. (2005) demonstrated a significant reduction of tricuspid E/A ratio with age, while in Watanabe et al. (2005) showed reduction to be much less pronounced. Similarly Pye et al. (1991) found no significant correlation between any of the tricuspid flow variables and age.

The variation of early diastolic filling rate in respect of the load changes reflects the normal variation of diastolic load of the right ventricle, when constrictive 
Table 4. Tricuspid flow parameters according to various authors.

\begin{tabular}{|c|c|c|c|c|c|c|c|}
\hline Author & $\begin{array}{l}\text { Number } \\
\text { of persons }\end{array}$ & $\begin{array}{l}\text { Age } \\
\text { [years] }\end{array}$ & $\begin{array}{l}\mathrm{E} \\
{[\mathrm{cm} / \mathrm{s}]}\end{array}$ & $\begin{array}{l}\text { A } \\
{[\mathbf{c m} / \mathbf{s}]}\end{array}$ & $\mathbf{E} / \mathbf{A}$ & $\begin{array}{l}\text { Sample } \\
\text { volume }\end{array}$ & Conditions \\
\hline Hatle et al. 1989 & 20 & $45 \pm 9$ & $\begin{array}{l}56 \pm 9 \\
64 \pm 10\end{array}$ & $\begin{array}{l}39 \pm 6 \\
44 \pm 6\end{array}$ & & $\begin{array}{l}\text { between } \\
\text { the tips }\end{array}$ & $\begin{array}{l}\text { expirium } \\
\text { inspirium }\end{array}$ \\
\hline Chakko et al. 1990 & 10 & not given & $52 \pm 1$ & $31 \pm 7$ & $1.7 \pm 0.4$ & $\begin{array}{l}\text { between } \\
\text { the tips }\end{array}$ & $\begin{array}{l}\text { respiratory phase } \\
\text { not specified }\end{array}$ \\
\hline Odake et al. 1991 & 7 & mean 54 & $\begin{array}{l}36 \pm 7 \\
44 \pm 7\end{array}$ & $\begin{array}{l}35 \pm 7 \\
38 \pm 5\end{array}$ & $\begin{array}{l}1.0 \pm 1 \\
0.9 \pm 1\end{array}$ & $\begin{array}{l}\text { in the } \\
\text { tricuspid } \\
\text { annulus }\end{array}$ & $\begin{array}{l}\text { not specified } \\
\text { quick dextrane } \\
\text { infusion }\end{array}$ \\
\hline Pye et al. 1991 & 74 & mean 45 & $51 \pm 8$ & $35 \pm 9$ & & $\begin{array}{l}\text { between } \\
\text { the tips }\end{array}$ & inspirium \\
\hline $\begin{array}{l}\text { Mandysová } \\
\text { (unpublished data) }\end{array}$ & 31 & $35 \pm 10$ & $\begin{array}{l}50 \pm 7 \\
64 \pm 9\end{array}$ & $\begin{array}{l}34 \pm 7 \\
40 \pm 8\end{array}$ & $\begin{array}{l}1.5 \pm 3 \\
1.6 \pm 0.3\end{array}$ & $\begin{array}{l}\text { between } \\
\text { the tips }\end{array}$ & $\begin{array}{l}\text { expirium } \\
\text { inspirium }\end{array}$ \\
\hline
\end{tabular}

Data are mean \pm S.D.

pericarditis can be excluded (Hatle et al. 1989). The missing response of the early velocity of diastolic filling to volume load reflects the right ventricular affection, as can be seen in patients with the coronary heart disease (Odake et al. 1991).

Flow parameters are always more or less dependent on the loading conditions (Vasan et al.2000). Even if some authors consider some new parameter to be load independent or "relatively load-independent" (Garcia et al. 1999), detailed study usually finds that there is dependence.

Our results confirm relatively high variations of the peak early and late tricuspid flow velocities in response to preload changes in healthy subjects. The same is true for the velocity flow integrals.

\section{Normal respiration}

Variations of the diastolic tricuspid flow pattern are still distinctive during a normal tidal breathing being more pronounced than those of the mitral inflow (Mandysová et al. 1995). They reflect the cyclic variations of the right ventricular load with the respiratory cycle (Odake et al. 1991). The increase of the early peak filling velocity is higher $(29 \%)$ than that of the late peak filling velocity (19\%), reflecting the fact that in healthy subjects the inspiratory preload increase influences more the early filling than the atrial contribution. This implies the slight inspiratory increase of the E/A value. These changes reflect the known physiological situation of the increased venous return (especially from vena cava superior) to the right heart during inspiration.

\section{Acute preload changes}

A pronounced acute increase of the right ventricular preload set up by the elevation of the lower extremities causes a substantial increase of the peak early filling velocity of tricuspid flow ( $42 \%$ in comparison with baseline values) and a significant, but less pronounced increase of the peak late filling velocity $(24 \%)$.

The $\mathrm{E} / \mathrm{A}_{\mathrm{el}}$ is higher $(=0.7)$ in comparison with $\mathrm{E} / \mathrm{A}$ in the inspiration phase $(=0.5)$. This finding documents the fact that the higher the increase of preload, the higher the contribution of the early filling to the whole right ventricular diastolic flow.

\section{Increase of afterload}

Peak velocities of the early and the late diastolic filling increased slightly with handgrip (6\% and $9 \%$, respectively.) and their ratio did not change significantly. Marked increase of the A velocity (and consequent E/A decrease) typical for a prolonged dynamic exercise has not been observed in the handgrip test. This finding reflects the different behavior of the right ventricle with respect to the type of the load: In dynamic exercise (Douglas et al. 1988), the pulmonary arterial pressure rises more than the systemic one and the right ventricular stroke work (for a given workload) increases more than that of the left ventricular one. However, isometric exercise changes neither the pulmonary artery pressure nor the resistance (Fisher et al. 1973).

Our finding of a slight increase of the $\mathrm{E}$ and $\mathrm{A}$ velocities with the handgrip can be explained by either a 
slight increase of cardiac output, end-diastolic right ventricular pressure and heart rate (Mandysová et al. $1995)$ in a given load.

All pre- and afterload changes in our group of healthy subjects lead to systematic, but individually more or less pronounced changes of measured values. Some studies document age changes of the diastolic tricuspid flow pattern which are usually less pronounced than those of the mitral one (Watanabe et al. 2005). However, as our study was based only on pair observations, the age related changes cannot be considered.

\section{Limitations}

The studied subjects were proclaimed healthy on the basis of a negative medical history and a normal physical examination. No other methods for exclusion of coronary heart disease were used.

Heart rate changes ranged within physiological limits in all patients and changed only slightly during the study (non-significant differences between studied groups). The number of cases studied was low for applying multiple testing of dependence among variables. "Cycle by cycle" and "day after day" reproducibility was not studied.

Our results can be applied only to healthy subjects.

\section{Acknowledgements}

Supported by the Grant of the Czech Academy of Scences No 74753.

\section{References}

APPLETON CHP, HATLE LK, POPP RL: Relation of transmitral flow velocity patterns to left ventricular diastolic function: new insights from a combined hemodynamic and Doppler echocardiographic study. $\mathrm{J} \mathrm{Am} \mathrm{Coll}$ Cardiol 12: 426-440, 1988.

CHAKKO S, MARCHENA E, KESSLER KM, MATERSON BJ, MEYRBURG RJ: Right ventricular diastolic function in systemic hypertension. Am J Cardiol 65: 1117-1120, 1990.

DABESTANI A, TAKENAKA K, ALLLEN B, GARDIN JM, FISCHER, S, RUSSELL D, HENRY WL: Effects of spontaneous respiration on diastolic left ventricular filling assessed by pulsed Doppler echocardiography. $\mathrm{Am} J$ Cardiol 61: 1356-1358, 1988.

DOUGLAS PP, BERKO B, IOLI A, PARR C, REICHEK N: Relation of Doppler indices to other measures of diastolic left ventricular function. $J$ Am Coll Cardiol 11: 119A, 1988.

EMILSSON K, LOISKE K, OHLIN B. Comparison between maximal early diastolic velocity in long-axis direction obtained by M-mode echocardiography and by tissue Doppler in the assessment of right ventricular diastolic function. Clin Physiol Funct Imaging 25: 178-82, 2005.

FISHER ML, NUTTER DO, JACOBS W, SCHLANT RC: Hemodynamic responses to isometric exercise (handgrip) in patients with heart disease. Br Heart J 35: 422-432, 1973.

GARCIA MJ, PALAC RT, MALENKA DJ, TERRELL P, PLEHN JF: Color M-mode Doppler flow propagation velocity is a relatively preload-independent index of left ventricular filling. $J$ Am Soc Echocardiogr 12: 129137, 1999.

HATLE LK, APPLETON CHP, POPP RL: Differentiation of constrictive pericarditis and restrictive cardiomyopathy by Doppler echocardiography. Circulation 79: 357-376, 1989.

LINDQVIST P, WALDENSTROM A, HENEIN M, MORNER S, KAZZAM E: Regional and global right ventricular function in healthy individuals aged 20-90 years: a pulsed Doppler tissue imaging study: Umea General Population Heart Study. Echocardiography 22: 305-314, 2005.

MANDYSOVÁ E, NIEDERLE P, GAĎOUREK P, MANDYS F: Tricuspid flow variations under various physiologic conditions. Cor Vasa 37: 168-174, 1995.

MELUZÍN J, ŠPINAROVÁ L, HUDE P, KREJČÍ J, KINCL V, PANOVSKÝ R, DUŠEK L: Prognostic importance of various echocardiographic right ventricular functional parameters in patients with symptomatic heart failure. $J$ Am Soc Echocardiogr 18: 435-444, 2005.

MCDICKEN WN, SUTHERLAND GR, MORAN CM, GORDON LN: Colour Doppler velocity imaging of the myocardium. Ultrasound Med Biol 18: 651-654, 1992. 
ODAKE M, TAKEUCHI M, FUKUZAKI H: Doppler assessment of right ventricular filling dynamics during volume loading in ischemic heart disease. Clin Cardiol 14: 402-408, 1991.

PYE MP, PRINGLE SD, COBBE SM: Reference values and reproducibility of Doppler echocardiography in the assessment of the tricuspid valve and right ventricular diastolic function in normal subjects. Am J Cardiol 67: 269-273, 1991.

ROKEY R, KUO LC, ZOGHBI WA, LIMACHER MC, QUINNONES MA: Determination of parameters of left ventricular diastolic filling with pulsed Doppler echocardiography: comparison with cineangiography. Circulation 71: 533-550, 1985.

SPIRITO P, MARON BJ, VERTER I, MERRILL JS: Reproducibility of Doppler echocardiographic measurements of left ventricular diastolic function. Eur Heart J 9: 879-886, 1988.

VASAN RS, LEVY D, LARSON MG, BENJAMIN EJ: Interpretation of echocardiographic measurements: A call for standardization. Am Heart J 139: 412-422, 2000.

WATANABE S, SUZUKI N, KUDO A, SUZUKI T, ABE S, SUZUKI M, KOMATSU S, SAIJO Y, MURAYAMA N: Influence of aging on cardiac function examined by echocardiography. Tohoku J Exp Med 207: 13-19, 2005.

\section{Corresponding author}

Eva Mandysová, Hospital na Homolce, Roentgenova 2, 15030 Prague 5, Czech Republic. E-mail: eva.mandysova@homolka.cz 